\author{
Junying Liu ${ }^{1,2}$ \\ Wenhui Lu ${ }^{2}$ \\ Huitao Liu ${ }^{1}$ \\ Xiaqing $\mathrm{Wu}^{2}$ \\ Jinhua $\mathrm{Li}^{2}$ \\ Lingxin Chen ${ }^{1,2 *}$ \\ ${ }^{1}$ College of Chemistry and \\ Chemical Engineering, Yantai \\ University, Yantai, P. R. China \\ ${ }^{2}$ Key Laboratory of Coastal \\ Environmental Processes and \\ Ecological Remediation, \\ Shandong Provincial Key \\ Laboratory of Coastal \\ Environmental Processes, \\ Yantai Institute of Coastal Zone \\ Research, Chinese Academy of \\ Sciences, Yantai, P. R. China
}

Received November 11, 2015

Revised April 1, 2016

Accepted April 4, 2016
Research Article

\section{Dispersive liquid-liquid microextraction for four phenolic environmental estrogens in water samples followed by determination using capillary electrophoresis}

Dispersive liquid-liquid microextraction (DLLME) coupled with CE was successfully developed for simultaneous determination of four types of phenolic environmental estrogens (PEEs), namely hexestrol (HS), bisphenol A (BPA), diethylstilbestrol (DES) and dienestrol (DS). Several parameters affecting DLLME and CE conditions were systematically investigated including the type and volume of extraction solvent and dispersive solvent, extraction time, salt, $\mathrm{pH}$ value, surfactant, buffer solution and so on. Under the optimal conditions, DLLME-CE exhibited strong enrichment ability, presenting high enrichment factors of 467, 241, 367 and 362 for HS, BPA, DES and DS, respectively, as well as low detection limits of $0.3,0.6,0.6$ and $0.3 \mu \mathrm{g} / \mathrm{L}$, respectively. Excellent linearity was achieved in the range of 2.0-150 $\mu \mathrm{g} / \mathrm{L}$ for HS and DS, and 4.0-300 $\mu \mathrm{g} / \mathrm{L}$ for BPA and DES, with correlation coefficients $R>0.9983$. Recoveries ranging from 70.4 to $108.1 \%$ were obtained with tap water, lake water and seawater samples spiked at three concentration levels and the relative standard deviations (RSDs, for $n=5$ ) were 2.1-9.7\%. This DLLME-CE method with high selectivity and sensitivity, high stability, simplicity, cost-effectiveness, eco-friendliness was proved potentially applicable for the rapid and simultaneous determination of PEEs in complicated water samples.

Keywords:

Capillary electrophoresis / Dispersive liquid-liquid microextraction / Phenolic environmental estrogens / Water samples

DOI 10.1002/elps.201500519

Additional supporting information may be found in the online version of this article at the publisher's web-site

\section{Introduction}

Estrogens belong to the endocrine-disrupting chemicals which can affect endocrine system of human being prominently [1]. Hexestrol (HS), bisphenol A (BPA), diethylstilbestrol (DES) and dienestrol (DS) are the four important kinds of artificially synthesized phenolic environmental estrogens (PEEs) and they are difficult to separate because of the strucure similarity. They have been used to treat various diseases caused by the deficiency of estrogens such as as growth promoter. On the other hand, it has been recognized that

Correspondence:Professor Huitao Liu

E-mail: liuht-ytu@163.com

Abbreviations: BPA, bisphenol A; CPE, cloud-point extraction; DES, diethylstilbestrol; DLLME, dispersive liquid-liquid microextraction; DS, dienestrol; EF, enrichment factor; HS, hexestrol; PEEs, phenolic environmental estrogens; SPME, solid-phase microextraction estrogens are widely present in the environmental waters, sediments and some aquatic product matrices, by means of industrial, agricultural and municipal effluents and owing to the arbitrary and illegal additon [2,3]. The concentration level of the estrogens is found in the environmental matrices ranging from not detected to $10 \mathrm{ng} / \mathrm{g}$, and possibly higher in the polluted rivers [4]. These estrogens can enter human body through food chain and make metabolic disorders and even cause tumors such as breast cancer and prostate cancer [5-7]. Furthermore, some findings indicate their estrogenic effects occur on organism ususally at the concentration level of lowng/L $[3,4,8]$. In some countries and regions, such as United States, European Union members and Japan, the maximum residue limits for some PEEs in water have been established, i.e., $0.1 \mathrm{ng} / \mathrm{mL}$ or lower. Hence, it is necessary and important to develop simple, fast and effective methods for monitoring the presence and detecting the levels of estrogens.

*Additional corresponding author: Professor Lingxin Chen E-mail: 1xchen@yic.ac.cn 
Recently, estrogens detection has attracted serious attentions. Various analysis techniques have been developed to detect various matrical estrogens, including HPLC [9-11], liquid chromatography-mass spectrometry (LC-MS) [12,13], GC [14], CE $[15,16]$, CE coupled to mass spectrometry (CEMS) $[17,18]$, immunoassay [19] and so on. CE has the advangtages of low solvent consumption, high seperation efficiency, automatic operation and it has been developing quickly [15-18, [20]]. MEKC, one mode of CE, attributes its migration principle to electrophoresis and its separation principle to chromatography, and it enables the application range of CE to be expanded to neutral compounds [21,22].

On the other hand, considering their low concentration presence in complicated matrices, a number of pretreatment approaches have been developed to concentrate the estrogens and decontaminate environmental samples. For examples, liquid-liquid extraction [17, 23] SPE [24, 25], solid-phase microextraction (SPME) [26, 27], stir bar sorptive extraction [28] and cloud-point extraction (CPE) [29] have been reported for estrogens. However, the classical extraction methods, liquidliquid extraction and SPE, require large volumes of organic solvents and long preparation time. Dispersive liquid-liquid microextraction (DLLME) first introduced in 2006 [30] has the advantages of simplicity, rapidity and high enrichment ability, which shows a wide aplication prospect in the analysis of organic compounds and metal ions, and even in the speciation analysis of trace elements [31].

In this work, the four types of estrogens including HS, BPA, DES and DS in water samples were simultaneously concentrated, separated and detected using DLLME coupled with CE. The method demonstrated good analytical performances such as wide linear range, good reproducibility, low detection limit and high recovery. It was expected to provide an alternative for simultaneous determination of trace estrogens in water samples.

\section{Materials and methods}

\subsection{Reagents and samples}

Four PEEs standards of HS, BPA, DES and DS were purchased from Sigma-Aldrich (Shanghai, China), and appropriate amounts were dissolved in methanol at a concentration of $1000 \mathrm{mg} / \mathrm{L}$, respectively. SDS and carbon tetrachloride were purchased from Aladdin (Shanghai, China). Chromatographic grade acetonitrile, methanol, ethanol and chlorobenzene were all purchased from J\&K Chemical (Beijing, China). The other chemicals, such as sodium hydroxide, sodium tetraborate decahydrate $\left(\mathrm{Na}_{2} \mathrm{~B}_{4} \mathrm{O}_{7} \cdot 10 \mathrm{H}_{2} \mathrm{O}\right)$, acetone, carbon dichloride and chloroform were of analytical grade and were obtained from Sinopharm Chemical Reagent (Shanghai, China). Working standard solutions were prepared daily by diluting the stock solutions to the required concentrations using methanol and all standard solutions were stored in a refrigerator at $4^{\circ} \mathrm{C}$ for use. The water used throughout the work was produced by a Milli-Q ultrapure water system (Millipore, Bedford, MA, USA).
Tap water samples were collected when needed from our laboratory after it had flowed for about $5 \mathrm{~min}$. Lake water samples were collected into a teflon bottle from an artificial lake named Sanyuan Lake located in the schoolyard of Yantai University. Surface seawater samples were collected in seaside close to the east gate of Yantai University. All water samples were filtrted through microporous nylon filters with a pore diameter of $0.45 \mu \mathrm{m}$ before use and protected from light.

\subsection{Apparatus and CE conditions}

A P/ACE MDQ CE system (Beckman Coulter, Fullerton, CA, USA) in conjunction with a DAD was used to separate the estrogens. Bare fused-silica capillaries, with id of $75 \mu \mathrm{m}$, od of $375 \mu \mathrm{m}$, total length of $50.2 \mathrm{~cm}$ and effective length of $40 \mathrm{~cm}$ (Yongnian Photoconductive Fiber Factory, Hebei, China), were used throughout the whole experiment. The $\mathrm{pH}$ of the buffer solution was calibrated by a pHS-3C digital $\mathrm{pH}$ meter (Hangzhou Dongxing Instrument Factory, Hangzhou, China). A new capillary was initialized by rinsing with water for $10 \mathrm{~min}, 1.0 \mathrm{M} \mathrm{NaOH}$ for $40 \mathrm{~min}$, water for $10 \mathrm{~min}$ and running buffer for $30 \mathrm{~min}$ before use. The capillary was rinsed with running buffer for 3 min between analyses. All solutions were filtered through microporous nylon filters with a pore diameter of $0.45 \mu \mathrm{m}$ before use. The detection wavelength was set at $228 \mathrm{~nm}$. The injection pressure was applied at $0.5 \mathrm{psi}$ for $5 \mathrm{~s}$ and separation voltage at $28 \mathrm{kV}$. The running buffer consisted of $10 \mathrm{mM} \mathrm{Na}_{2} \mathrm{~B}_{4} \mathrm{O}_{7} \cdot 10 \mathrm{H}_{2} \mathrm{O}, 20 \mathrm{mM} \mathrm{SDS}$, and $40 \%$ (v/v) acetonitrile, adjusted to $\mathrm{pH} 10.8$ with $1 \mathrm{M} \mathrm{NaOH}$.

\subsection{DLLME procedure}

For the DLLME, $10 \mathrm{~mL}$ aqueous sample solution containing HS, BPA, DES and DS was placed into a $15 \mathrm{~mL}$ centrifuge tube with conical bottom. The mixture of extraction solvent (chlorobenzene, $80 \mu \mathrm{L}$ ) and disperser solvent (acetone, $1000 \mu \mathrm{L}$ ) was quickly injected into the aqueous sample using a syringe and then the mixture was gently shaken with hand. Chlorobenzene was dispersed throughout the aqueous phase and a cloudy solution of fine droplets was formed. After the cloudy solution was centrifuged for $5 \mathrm{~min}$ at 5000 rpm, the extracting solvent containing the analytes was sedimented at the bottom of the tube. The supernatant liquid was removed and deserted, and the sedimentation phase was transferred to a smaller-sized centrifuge tube followed by drying under a gentle flow of nitrogen. Finally, the residue was redissolved with $20 \mu \mathrm{L}$ methanol for further CE analysis. The schematic illustration of the DLLME-CE procedure is shown in Supporting Information Fig. S1.

\subsection{Enrichment factor}

Enrichment factor (EF) was used to evaluate the extraction efficiency, and was calculated as the ratio of $C_{\text {sed }}$ to $C_{0}$, where $C_{\text {sed }}$ is the concentration of analyte in the sedimented phase, 
and $C_{0}$ is the initial concentration of analyte in the aqueous solution.

\section{Results and discussion}

\subsection{Optimization of CE conditions}

Initially, we purposed to use MEKC mode for the separation of the four PEEs by referring to the previous work [29, 32]. Factors affecting separation were optimized including running buffer, surfactant, organic modifier and applied voltage. Firstly, we investigated two types of buffer solutions, i.e., $\mathrm{Na}_{2} \mathrm{~B}_{4} \mathrm{O}_{7} \cdot 10 \mathrm{H}_{2} \mathrm{O}$ and $\mathrm{NaH}_{2} \mathrm{PO}_{4}$. Result showed that the chromatographic peaks of the four PEEs were deteriorated, let alone baseline separation in the $\mathrm{NaH}_{2} \mathrm{PO}_{4}$ solutions. Interestingly, $\mathrm{Na}_{2} \mathrm{~B}_{4} \mathrm{O}_{7} \cdot 10 \mathrm{H}_{2} \mathrm{O}$ presented better peak shape and resolution. Consequently, different concentrations of $\mathrm{Na}_{2} \mathrm{~B}_{4} \mathrm{O}_{7} \cdot 10 \mathrm{H}_{2} \mathrm{O}(5,10,15,20,30 \mathrm{mM})$ were optimized. $10 \mathrm{mM} \mathrm{Na} 2 \mathrm{~B}_{4} \mathrm{O}_{7} \cdot 10 \mathrm{H}_{2} \mathrm{O}$ offered higher peak height than that of $5 \mathrm{mM}$, and the four PEEs were not separated well as the concentrations exceeded $10 \mathrm{mM}$. According to our experiences and related literatrues, SDS was employed as surfactant micell. The concentrations of SDS $(10,15,20,25,30 \mathrm{mM})$ were tested. As shown in Supporting Information Fig. S2, better peak shape and higher resolution could be obtained when SDS was at $20 \mathrm{mM}$, which was also time-saving than that of $30 \mathrm{mM}$ with base-line separation. So, the MEKC was established by using the solution composing of $10 \mathrm{mM}$ $\mathrm{Na}_{2} \mathrm{~B}_{4} \mathrm{O}_{7} \cdot 10 \mathrm{H}_{2} \mathrm{O}$ and $20 \mathrm{mM}$ SDS.

The buffer $\mathrm{pH}$ is also one important parameter for separation because it can affect the ionization of analytes and further alter their electrophoretic mobility [33]. The $\mathrm{pH}$ values of $10.70,10.75,10.80,10.85$ and 10.90 were investigated, which were adjusted by $1.0 \mathrm{M} \mathrm{NaOH}$. As shown in Supporting Information Fig. S3, the larger peak-height value was achieved with the $\mathrm{pH}$ value of 10.80 , while at $\mathrm{pH}$ of 10.90 , the peaks of BPA and DES could not be well resolved. Thus, the buffer $\mathrm{pH}$ was adjusted to 10.80 for the following work.

The addition of organic modifier to the MEKC buffers was an effective way of improving separation selectivity, efficiency and resolution. We selected acetonitrile as the organic modifier in MEKC for its superior electroosmotic flow (EOF)-promoting ability [20]. The proportion of acetonitrile $(30,35,40,45,50 \%(\mathrm{v} / \mathrm{v}))$ was investigated. Related electrophoretograms were shown in Supporting Information Fig. S4. As observed, 40\% (v/v) provided more smooth peak shape with higher resolution and relatively short separation time. Hence, $40 \%$ (v/v) ACN was chosen, although the critical micelle concentration of SDS is higher than 30 $\mathrm{mM}$ for a volume fraction of ACN of 40\% [34]. However, if no SDS was added, the four PEEs could not be separated with EOF; and a higher concentration of SDS caused longer migration time and distorted peaks. Although it is hardly possible to form conventional micelles for the 20 $\mathrm{mM}$ SDS in the $40 \% \mathrm{ACN}$ solution [34], the appropriate concentration SDS $(20 \mathrm{mM})$ played an important role for
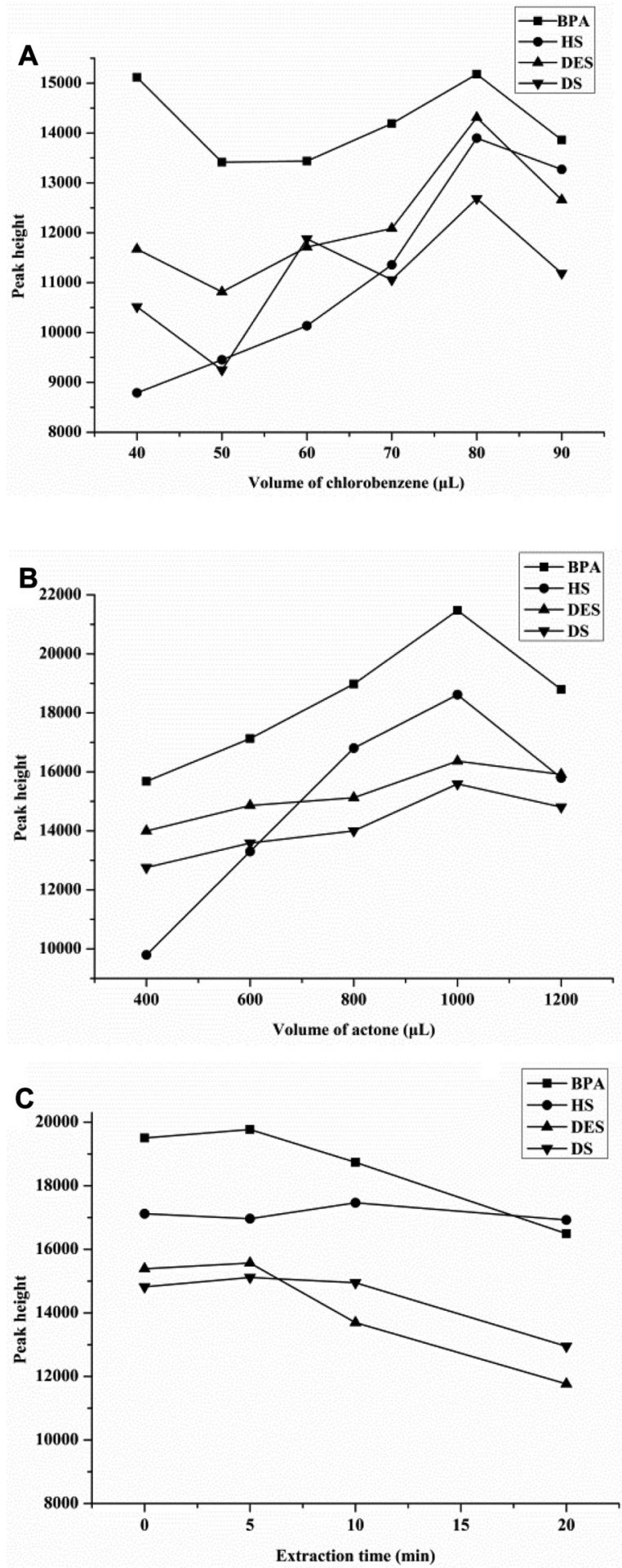

Figure 1. Effect of (A) extraction solvent volume, (B) dispersive solvent volume and $(C)$ extraction time on the peak height of the four PEEs. Extraction conditions: (A) sample volume, $10 \mathrm{~mL}$; dispersive solvent, $0.8 \mathrm{~mL}$ acetone; extraction solvent, chlorobenzene; (B) sample volume, $10 \mathrm{~mL}$; extraction solvent, $80 \mu \mathrm{L}$ chlorobenzene; dispersive solvent, acetone; (C) sample volume, $10 \mathrm{~mL}$; extraction solvent, $80 \mu \mathrm{L}$ chlorobenzene; dispersive solvent, $0.8 \mathrm{~mL}$ acetone. CE conditions: $10 \mathrm{mM} \mathrm{Na} \mathrm{B}_{4} \mathrm{O}_{7} \cdot 10 \mathrm{H}_{2} \mathrm{O}$, $20 \mathrm{mM}$ SDS and $40 \%(\mathrm{v} / \mathrm{v})$ acetonitrile, $\mathrm{pH} 10.8$. 


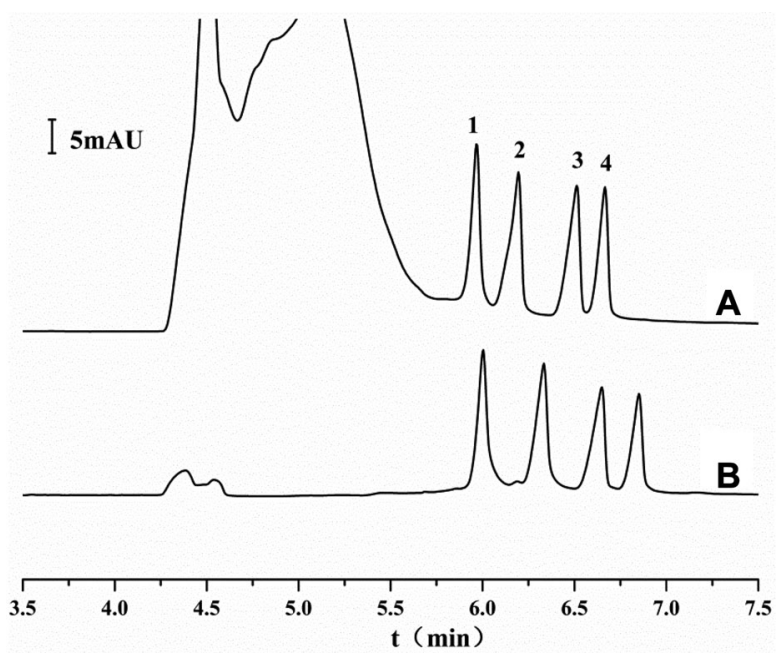

Figure 2. Electrophoregrams of the PEE standards with $(A)$ and without (B) DLLME. The concentrations of HS, BPA, DES and DS were $100,200,200$ and $100 \mu \mathrm{g} / \mathrm{L}$, respectively, for $(A)$, and 50, 50, 100 and $50 \mathrm{mg} / \mathrm{L}$, respectively, for (B). Peask: (1) HS, (2) BPA, (3) DES and (4) DS. CE conditions were the same as described in Fig. 1.

the separation. Accordingly, the named MEKC mode was possibly no longer applicable to the separation solution. So, the general name CE was used throughout the work. The results showed that the four PEEs could obtain excellent baseline separation within $7 \mathrm{~min}$, by using the running buffer solution consisting of $10 \mathrm{mM} \mathrm{Na} 2 \mathrm{~B}_{4} \mathrm{O}_{7} \cdot 10 \mathrm{H}_{2} \mathrm{O}, 20 \mathrm{mM}$ SDS and $40 \%(\mathrm{v} / \mathrm{v})$ acetonitrile, with $\mathrm{pH} 10.80$.

To further optimize the separation, voltages of 25,28 and $30 \mathrm{kV}$ were investigated. The voltages of $28 \mathrm{kV}$ could supply shorter separation time and higher peak height than $25 \mathrm{kV}$. The voltages of $30 \mathrm{kV}$ resulted in so big current that it affected the stability of baseline. So, the voltage of $28 \mathrm{kV}$ was adopted.

From the results above, the optimized CE conditions were confirmed: $10 \mathrm{mM} \mathrm{Na}{ }_{2} \mathrm{~B}_{4} \mathrm{O}_{7} \cdot 10 \mathrm{H}_{2} \mathrm{O}$ as buffer, $20 \mathrm{mM}$ SDS as surfactant, $40 \%(\mathrm{v} / \mathrm{v})$ acetonitrile as organic modifier, $\mathrm{pH}$ at 10.80 and separation voltage at $28 \mathrm{kV}$.

\subsection{Optimization of DLLME conditions}

In DLLME, there are several parameters that affect the extraction efficiency [35]. Some factors such as type and volume of extraction and dispersive solvents, salt effect, sample $\mathrm{pH}$ and extraction time were optimized. The most important point of the technique is to select appropriate extraction solvent and dispersive solvent.

\subsubsection{Selection of extraction solvent}

In DLLME, a good extraction solvent should have the following characteristics: density higher than water, high extraction capability of the interested analytes, low solubility in water and good chromatographic behavior [36]. Therefore, $\mathrm{CH}_{2} \mathrm{Cl}_{2}$,
$\mathrm{CHCl}_{3}, \mathrm{CCl}_{4}$ and $\mathrm{C}_{6} \mathrm{H}_{5} \mathrm{Cl}$ were selected as extraction solvents, with acetone as dispersive solvent. The results showed aqueous phase and organic phase were mutual after centrifugation when $\mathrm{CH}_{2} \mathrm{Cl}_{2}$ and $\mathrm{CHCl}_{3}$ were used as extraction solvents. $\mathrm{C}_{6} \mathrm{H}_{5} \mathrm{Cl}$ and $\mathrm{CCl}_{4}$ had the extraction ability for the four PEEs. And $\mathrm{C}_{6} \mathrm{H}_{5} \mathrm{Cl}$ had obviously superior extraction efficiency to BPA compared with $\mathrm{CCl}_{4}$. So, $\mathrm{C}_{6} \mathrm{H}_{5} \mathrm{Cl}$ was selected as the extraction solvent.

\subsubsection{Selection of dispersive solvent}

The dispersive solvent should meet the requirement of the good miscibility in both aqueous phase and extraction solvent, and then it enables the dispersion of fine droplets of the extractant into the aqueous phase containing the analytes. Based on the above considerations, methanol, ethanol, acetonitrile and acetone were examined. The results showed that acetone had the better enrichment effect than the others especially for BPA. Therefore, acetone was chosen as dispersive solvent.

\subsubsection{Selection of the volume of extraction solvent}

To examine the effect of extraction solvent volume on the extraction efficiency, the experiments were performed by using $0.8 \mathrm{~mL}$ acetone containing different volumes of $\mathrm{C}_{6} \mathrm{H}_{5} \mathrm{Cl}(40$, 50, 60, 70, 80, $90 \mu \mathrm{L}$ ). As shown in Fig. 1A, the extraction efficiency increased with the increase of extracting volume from 40 to $80 \mu \mathrm{L}$, and then decreased with further increasing extracting volume. Hence, $80 \mu \mathrm{L} \mathrm{C}_{6} \mathrm{H}_{5} \mathrm{Cl}$ was chosen as extraction solvent for the following studies.

\subsubsection{Selection of the volume of dispersive solvent}

The optimized DLLME conditions, the volume of dispersive solvent was also investigated by using different volumes of acetone $(0.4,0.6,0.8,1.0,1.2 \mathrm{~mL})$ with the fixed volumes of $\mathrm{C}_{6} \mathrm{H}_{5} \mathrm{Cl}(80 \mu \mathrm{L})$. As shown in Fig. 1B, the extraction efficiency was the maximum when the volume of acetone was $1.0 \mathrm{~mL}$. This was mainly because that, in the lower volumes of acetone, $\mathrm{C}_{6} \mathrm{H}_{5} \mathrm{Cl}$ was not dispersed well and the cloudy state was not formed well, so the extraction efficiency was relatively low. The solubility of the analytes in the aqueous phase was increased when higher volumes acetone was added. So, $1.0 \mathrm{~mL}$ of acetone was chosen as the optimum volume.

\subsubsection{Effect of extraction time}

In DLLME, extraction time is referred to the interval time, between the injection of the mixture of extraction solvent $\left(\mathrm{C}_{6} \mathrm{H}_{5} \mathrm{Cl}\right)$ and dispersive solvent (acetone), and the time starting to centrifugate. The time from 0 to $30 \mathrm{~min}$ was invesgated. As is shown in Fig. 1C, extraction time had no 
Table 1. Comparison of LOD and EF for PEEs determination using DLLME-CE with other CE and HPLC methods

\begin{tabular}{|c|c|c|c|c|c|c|}
\hline $\begin{array}{l}\text { Detection } \\
\text { technique }\end{array}$ & $\begin{array}{l}\text { Pretreatment } \\
\text { technique }\end{array}$ & LOD ( $\mu \mathrm{g} / \mathrm{L})$ & EF & $\begin{array}{l}\text { Extraction } \\
\text { time (min) }\end{array}$ & $\begin{array}{l}\text { Separation } \\
\text { time (min) }\end{array}$ & Ref. \\
\hline CE-DAD & DLLME $^{a)}$ & $0.3,0.6,0.6,0.3$ & $467,241,367,362$ & A few seconds & 7 & This work \\
\hline CE-UV & $\mathrm{dCPE}{ }^{\mathrm{b})}$ & $7.9,8.9,8.2$ & $50-150$ & 40 & 7 & [29] \\
\hline HPLC-UV & $\mathrm{dSPE}^{\mathrm{cl}}$ & $3.0,6.1,0.2$ & - & 40 & 8 & [37] \\
\hline HPLC-DAD & UA-CPE ${ }^{d)}$ & $0.1,0.2,0.1$ & $78.39,94.34,86.59$ & 45 & 11 & [10] \\
\hline HPLC-UV & DLLME $^{\mathrm{e})}$ & 0.07 & - & A few seconds & 4 & [11] \\
\hline HPLC-UV & MMIPs-SPMEF' & $1.5-5.5$ & - & 20 & 14 & [27] \\
\hline HPLC-UV & DLLMEg) $^{g}$ & $0.010,0.010,0.008$ & $71,78.5,73.5$ & A few seconds & 10 & [35] \\
\hline
\end{tabular}

a) Four analytes are HS, BPA, DES and DS, respectively.

b) Dual cloud point extraction. Three analytes are HS, DES and DS, respectively.

c) Dispersive SPE. Analytes are BPA, DES and DS, respectively.

d) Ultrasound-assisted cloud-point extraction. Analytes are 17 $\beta$ - stradiol (E2), estrone (E1) and DES.

e) Analyte is BPA.

f) Solid-phase microextraction method based on magnetic molecularly imprinted polymer as fiber coating. Analytes are E1, E2, estriol (E3) and DES.

g) Analytes are E1, E2 and DES.

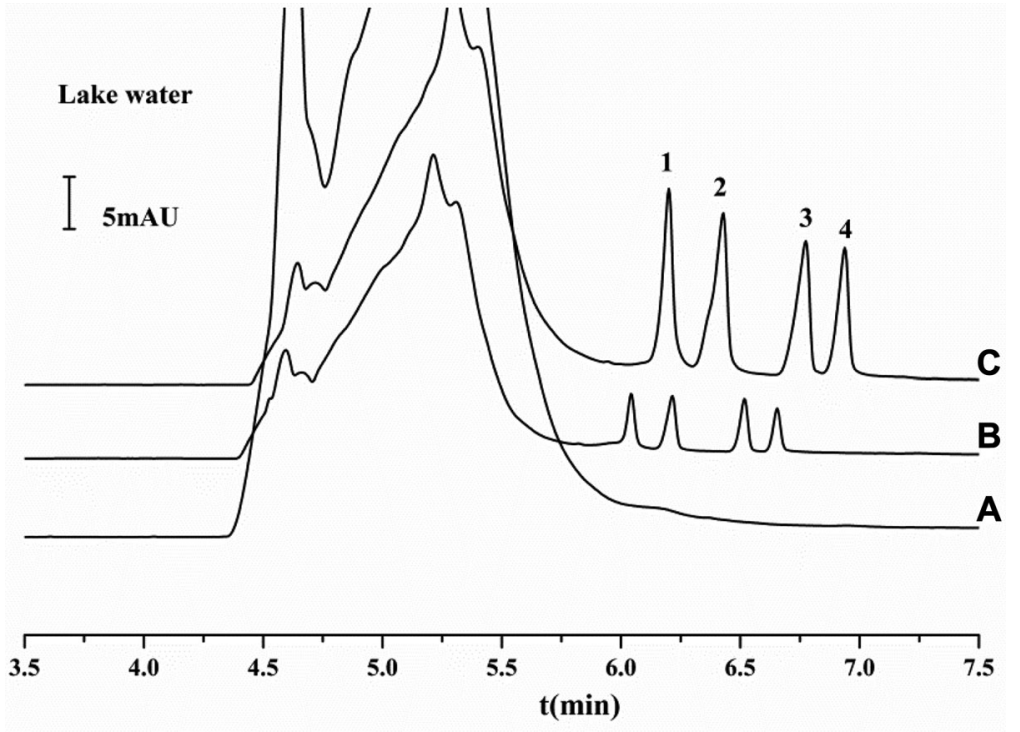

Figure 3. Electrophoregrams of lake water samples after DLLME without spiking (A), and spiked with HS, BPA, DES and DS at 25, 50, 50 and $25 \mu \mathrm{g} / \mathrm{L}$, respectively, (B) and spiked with HS, BPA, DES and DS at 100, 200, 200 and $100 \mu \mathrm{g} / \mathrm{L}$, respectively, (C). Peaks: (1) HS, (2) BPA, (3) DES and (4) DS. CE conditions were the same as described in Fig. 1. significant effect on extraction efficiency at the initial $10 \mathrm{~min}$. The reason is that the surface area between the extractant solvent and the aqueous phase is infinitely large and could equilibrate very quickly. The peak height slightly decreased when the time exceeded $10 \mathrm{~min}$ (Fig. 1C) mainly because the PEEs were dissolved in the water samples again. Therefore, centrifugation should be immediately performed after a cloudy solution of fine droplets was formed. That is, extraction time is quite short (usually within a few seconds), which is exactly a major advantage of DLLME.

\subsubsection{Effect of salt}

The effect of salt on the extraction efficiency was evaluated by adding $\mathrm{NaCl}(0-5 \%, \mathrm{w} / \mathrm{v})$ into the aqueous solution. That is, the addition of $1,2,3,4$ and $5 \% \mathrm{NaCl}$ was examined, respectively. When the concentration was lower than $3 \%$, it was observed that the salt did not have significant effects on peak shape, separation resolution and reproducibility, and only extraction efficiency was slightly increased according to peak height calculation, owing to slightly increased solubility of PEEs. When the concentration increased from 3-5\%, the peak shape, separation resolution and reproducibility became undesirable, as well as peak height decreased leading to decreased extraction efficiency, which may be because the solubility of PEEs decreased by increasing salt concentration. Considering the slight difference, for simplicity, hence, $\mathrm{NaCl}$ was not added in the subsequent experiments.

In short, the DLLME conditions were optimized, i.e., $\mathrm{C}_{6} \mathrm{H}_{5} \mathrm{Cl}$ as extraction solvent with $80 \mu \mathrm{L}$, acetone as dispersive solvent with $1.0 \mathrm{~mL}$, without additon of salt.

\subsection{Method performance}

Under the above optimized separation and extraction conditions, the four PEEs were separated well by CE. Figure 2 
Table 2. Recoveries and precisions (RSDs) a) of the four PEEs spiked in the real water samples $(n=5)$

\begin{tabular}{|c|c|c|c|c|c|c|c|}
\hline \multirow[t]{2}{*}{ PEEs } & & \multicolumn{2}{|l|}{ Tap water } & \multicolumn{2}{|l|}{ Lake water } & \multicolumn{2}{|l|}{ Seawater } \\
\hline & Added $(\mu \mathrm{g} / \mathrm{L})$ & Recovery (\%) & RSD (\%) & Recovery (\%) & RSD (\%) & Recovery (\%) & $\overline{R S D}(\%)$ \\
\hline \multirow[t]{3}{*}{ HS } & 5 & 79.4 & 7.2 & 70.9 & 5.6 & 86.3 & 5.2 \\
\hline & 25 & 94.2 & 5.1 & 72.6 & 4.5 & 77.8 & 7.3 \\
\hline & 100 & 99.4 & 5.6 & 102.2 & 7.6 & 97.9 & 6.7 \\
\hline \multirow[t]{3}{*}{ BPA } & 10 & 77.0 & 7.6 & 77.7 & 7.9 & 89.0 & 7.8 \\
\hline & 50 & 99.7 & 2.7 & 90.1 & 7.3 & 108.1 & 7.3 \\
\hline & 200 & 103.0 & 5.1 & 97.5 & 7.2 & 104.4 & 5.7 \\
\hline \multirow[t]{3}{*}{ DES } & 10 & 75.5 & 9.3 & 91.2 & 9.1 & 78.7 & 5.6 \\
\hline & 50 & 105.6 & 3.8 & 104.2 & 6.2 & 107.8 & 7.7 \\
\hline & 200 & 95.7 & 5.9 & 90.7 & 2.1 & 95.4 & 3.3 \\
\hline \multirow[t]{3}{*}{ DS } & 5 & 81.7 & 5.4 & 70.4 & 9.7 & 80.8 & 8.9 \\
\hline & 25 & 96.2 & 3.9 & 98.2 & 5.7 & 104.1 & 3.5 \\
\hline & 100 & 95.3 & 4.0 & 95.1 & 5.8 & 95.1 & 3.9 \\
\hline
\end{tabular}

a) Relative standard deviations.

shows comparative electropherograms of PEEs standards with (curve a) and without (curve b) DLLME procedure. As seen, the peak height of four PEEs at 100 or $200 \mu \mathrm{g} / \mathrm{L}$ each (curve a) approximated that obtained at 50 or $100 \mathrm{mg} / \mathrm{L}$ each (curve b), a 250- or 500-fold higher concentration. Thus, it can be estimated that the EF values due to DLLME were 467, 241, 367 and 362 for HS, BPA, DES and DS, respectively, suggesting the DLLME had high enrichment ability.

Furthermore, the analytical performances of DLLME-CE for PEEs were investigated. Relationship between peak height and concentrations was assessed by using five different concentrations, and good linearity was attained in the range of 2.0-150 $\mu \mathrm{g} / \mathrm{L}$ for HS and DS, and 4.0-300 $\mu \mathrm{g} / \mathrm{L}$ for BPA and DES, with correlation coefficients $(R)$ over 0.9983 . The limits of detection (LODs) determined based on the $\mathrm{S} / \mathrm{N}$ of 3 , were $0.3,0.6,0.6$ and $0.3 \mu \mathrm{g} / \mathrm{L}$ for HS, BPA, DES and $\mathrm{DS}$, respectively. The values are close to the established maximum residue limits $(0.1 \mu \mathrm{g} / \mathrm{L})$ in nature water, and meet the requirement of trace analysis [26]. As well as, the method can be applied to analyze some wastewater samples especially from feed industry, where the PEEs are possibly present at $\mu \mathrm{g} / \mathrm{L}$ or higher. Therefore, the DLLME-CE-DAD method can reach the required levels for the four PEEs in environmental water investigations to some extent.

On the other hand, the RSDs obtained under repeatability conditions, namely the intra-day precisions in terms of migration time were $0.83-0.98 \%$, as listed in Supporting Information Table S1. In a meanwhile, under reproducibility conditions, i.e., the inter-day precisions were in the range of $2.46-3.53 \%$. Thus, the method was proved robust and reliable, and was capable of accurately quantifying PEEs.

In addition, the performances of our developed DLLMECE were compared with other reported CE and HPLC methods for the PEEs determination. As shown in Table 1, the LODs of our developed method are lower than that of dCPE-CE-DAD [29], dSPE-HPLC-UV [37] and MMIPs-SPMEHPLC-UV [27]. Moreover, the extraction time in DLLME is very short even within a few seconds. However, the abovementioned three methods require 20 or $40 \mathrm{~min}$ for extraction, without equilibrium in most cases. Although higher LODs and longer separation time are obtained compared with the method of DLLME-HPLC-UV [11], our method could simultaneously separate and detect the four PEEs, which has not been reported. More excitingly, the EFs of our method of 241-467 were higher than the method of dCPE-CE-DAD [29], UA-CPE-HPLC-DAD [10] and DLLME-HPLC-UV [35]. Overall, our developed method had obvious superiority based on the low LODs, high EF values and shorter analysis time. In addition, the method was quite simple, fast, cost-saving and eco-friendly. It was potentially suitable for the determination of estrogens in water samples.

\subsection{Analysis of real water samples}

In order to check the practical applicability of the developed method, three kinds of real water samples, i.e., tap water, lake water and seawater were investigated. Figure 3 shows the separation results of lake water samples; Supporting Information Fig. S5 shows the results of other two kinds of water samples. As seen, the endogenous PEEs were not detected in the three water samples (curve a). For the spiked water samples (curve b, c), the four types of PEEs attained complete base-line separation. Obviously, the analysis of the PEEs did not suffer from the interference from water matrices, which is quite probably because of the selective enrichment ability and good cleanup effect of DLLME. Table 2 lists the recoveries of the three water samples by adding three levels of the four PEEs standards. As shown from the table, recoveries ranged from 70.4 to $108.1 \%$, and the RSDs were obtained within 2.1$9.7 \%$. It is also noticeable that the recoveries are satisfactory for seawater samples, in some cases even better than that of tap and lake water. The observations are consistent with the aforementioned salt effect on DLLME. As is well known, seawater usually contains $2.7 \% \mathrm{NaCl}(\mathrm{w} / \mathrm{v})$, and herein, cleaner and lower salt surface seawater samples were used. Thus, the DLLME procedure was applicable for the tested seawater samples, with reasonable results. The developed method was 
demonstrated practically feasible for the simultaneous separation and determination of trace PEEs in complicated water samples.

\section{Concluding remarks}

A DLLME-CE method was developed for the separation and determination of four types of PEEs in water samples. By optimizing factors affecting the experiment, high EFs from 241 to 467 and low LODs from 0.3 to $0.6 \mu \mathrm{g} / \mathrm{L}$ were obtained. The method was successfully applied to three kinds of real water samples. The DLLME-CE method with simple UV detector was demonstrated to be a simple, fast, cost-effective and eco-friendly option for simultaneous separation and determination of trace PEEs in complicated aquous matrices.

On the other hand, more work still needs to be done to further improve the detection sensitivity and promote the advancement of the DLLME-CE method, such as investigating more new types of extraction and dispersive solvents for DLLME, utilizing computation tools for the optimization of influence factors of DLLME, developing various modalities of DLLME, and exploring various CE modes and on-line enrichment strategies. The dual/multiple CE stacking modes coupled with DLLME modified/derivatized and hyphenated techniques will provide remarkably larger EF and thereby ultrasensitive determination.

We are grateful for financial support from the National Natural Science Foundation of China (No. 51573155, 21477160, 21275158).

The authors have declared no conflict of interest.

\section{References}

[1] Chang, C. C., Huang, S. D., Anal. Chim. Acta 2010, 662, 39-43.

[2] Kuster, M., de Alda, M. J. L., Barceló, D., TrAC Trends Anal. Chem. 2004, 23, 790-798.

[3] Migeot, V., Dupuis, A., Cariot, A., Albouyâ€"Liaty, M., Pierre, F., Rabouan, S., Environ. Sci. Technol. 2013, 47, 13791-13797.

[4] Lei, B. L., Huang, S. B., Zhou, Y. Q., Wang, D. H., Wang, Z. J., Chemosphere 2009, 76, 36-42.

[5] Wang, Y. K., Wang, M., Wang, H. L., Wang, W. W., Wu, J., Wang, X. D., Food Chem. 2015, 173, 1213-1219.

[6] Giese, R. W., J. Chromatogr. A 2003, 1000, 401-412.

[7] Du, X. W., Wang, X. D., Li, Y. Y., Ye, F. O., Dong, Q. X., Huang, C. J., Chromatographia 2010, 71, 405410.

[8] Flint, S., Markle, T., Thompson, S., Wallace, E., J. Environ. Manag. 2012, 104, 19-34.

[9] Lima, D. L., Silva, C. P., Otero, M., Esteves, V. I., Talanta 2013, 115, 980-985.

[10] Zou, Y., Li, Y. H., Jin, H., Tang, H. N., Zou, D. Q., Liu, M. S., Yang, Y. L., Anal. Biochem. 2012, 421, 378-384.
[11] Rezaee, M., Yamini, Y., Shariati, S., Esrafili, A., Shamsipur, M., J. Chromatogr. A 2009, 1216, 1511-1514.

[12] Han, H., Kim, B., Lee, S. G., Kim, J., Food Chem. 2013, $140,44-51$.

[13] Gao, Q., Luo, D., Bai, M., Chen, Z. W., Feng, Y. Q., J. Agric. Food. Chem. 2011, 59, 8543-8549.

[14] Amelin, V. G., Korolev, D. S., Tret'yakov, A. V., J. Anal. Chem. 2015, 70, 419-423.

[15] Liu, S. F., Wu, X. P., Xie, Z. H., Lin, X. C., Guo, L. Q., Yan, C., Chen, G. N., Electrophoresis 2005, 26, 2342 2350.

[16] Fogarty, B., Dempsey, E., Regan, F., J. Chromatogr. A 2003, 1014, 129-139.

[17] D’Orazio, G., Asensio-Ramos, M., Hernández-Borges, J., Fanali, S., Rodríguez-Delgado, M. Á., J. Chromatogr. A 2014, 1344, 109-121.

[18] D’Orazio, G., Asensio-Ramos, M., Hernández-Borges, J., Rodríguez-Delgado, M. Á., Fanali, S., Electrophoresis 2015, 36, 615-625.

[19] Wang, L. J., Zhang, Y. F., Liu, G. F., Zhang, C. Y., Wang, S. H., Steroids 2014, 89, 41-46.

[20] Li, J. H., Chan, W., Cai, Z. W., Electrophoresis 2009, 30, 1790-1797

[21] Li, J. H., Cai, Z. W., Talanta 2008, 77, 331-339.

[22] Wen, Y. Y., Li, J. H., Ma, J. P., Chen, L. X., Electrophoresis 2012, 33, 2933-2952.

[23] Ternes, T. A., Andersen, H., Gilberg, D., Bonerz, M., Anal. Chem. 2002, 74, 3498-3504.

[24] Hu, W. Y., Kang, X. J., Zhang, C., Yang, J., Ling, R., Liu, E. H., Li, P., J. Chromatogr. B 2014, 957, 7-13.

[25] Morishima, Y., Hirata, Y., Jinno, K., Fujimoto, C., J. Liq. Chromatogr. Relat. Technol. 2005, 28, 3217-3228.

[26] Yang, Y., Chen, J., Shi, Y. P., Talanta 2012, 97, 222-228.

[27] Lan, H. Z., Gan, N., Pan, D. D., Hu, F. T., Li, T. H., Long, N. B., Qiao, L., J. Chromatogr. A 2014, 1331, 10-18.

[28] Hu, C., He, M., Chen, B. B., Hu, B., J. Agric. Food. Chem. 2012, 60, 10494-10500.

[29] Wen, Y. Y., Li, J. H., Liu, J. S., Lu, W. H., Ma, J. P., Chen, L. X., Anal. Bioanal. Chem. 2013, 405, 5843-5852.

[30] Rezaee, M., Assadi, Y., Hosseini, M. R. M., Aghaee, E., Ahmadi, F., Berijani, S., J. Chromatogr. A 2006, 1116, $1-9$.

[31] Ma, J. P., Lu, W. H., Chen, L. X., Curr. Anal. Chem. 2012, $8,78-90$.

[32] Liu, Y. L., Jia, L., Microchem. J. 2008, 89, 72-76.

[33] Chen, L. X., Lee, S., Choo, J., Lee, E. K., J. Micromech. Microeng. 2008, 18, 013001.

[34] Garcia-Alvarez-Coque, M. C., Maria, J., Angel, R., CardBroch, S., in: Anderson, J., Berthod, A., Pino, V., Stalcup, A. M. (Eds.), Micellar Liquid Chromatography: Fundamentals, Wiley-VCH, 2015, Volume 2, Part 1, Chapter 3.

[35] Hadjmohammadi, M. R., Ghoreishi, S. S., Acta Chim. Slov. 2011, 58, 765-771.

[36] Yang, F. F., Li, J. H., Lu, W. H., Wen, Y. Y., Cai, X. Q., You, J. M., Ma, J. P., Ding, Y. J., Chen, L. X., Electrophoresis 2014, 35, 474-481.

[37] Wen, Y. Y., Niu, Z. L., Ma, Y. L., Ma, J. P., Chen, L.X., J. Chromatogr. A 2014, 1368, 18-25. 